\title{
Produção do cuidado nas equipes de saúde da família: novas lentes para compreender a micropolítica do trabalho em saúde
}

\author{
The production of care within family healthcare teams: new lenses \\ through which to view the micro-politics of health work
}

\author{
Adriano Maia dos Santos \\ Professor do Instituto Multidisciplinar em Saúde/Universidade Federal da Bahia. \\ maiaufba@ufba.br
}

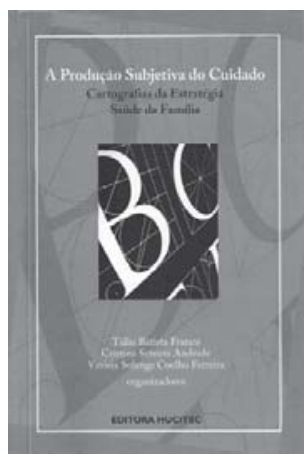

FRANCO, Túlio Batista; ANDRADE, Cristina Setenta; FERREIRA, Vitória Solange Coelho (Org.). A produção subjetiva do cuidado: cartografias da estratégia saúde da família. São Paulo: Hucitec, 2009. 164p.
$\mathrm{O}_{\text {mans }}$ conhecimento científico, apesar dos inúmeros avanços nas mais diferentes áreas do saber, abstém-se de valorizar investigações que tenham como referencial teórico questões subjetivas. Por conta disso, valores como cuidado, felicidade, desejo, afecções humanas, sensível e inaudível são delegados a um plano marginal, e as pesquisas que os ousam colocar em evidência acabam sendo incompreendidas, combatidas, interditadas, deslocadas para um espaço não científico, um não lugar, em favor da compreensão instrumental, sistêmica, que se toma como 'verdade' e, nesse ponto, passa a ser admitida como ciência.

Nas avaliações dos sistemas e serviços de saúde, a situação não é diferente: o lugar hegemônico é ocupado por estudos que permitem generalizações, evidenciam possíveis causas/efeitos, identificam o substrato material ou a intervenção instrumental capaz de 'provar', 'resolver', criar um 'bem de troca' passível de ser consumido ou verdades que muitas vezes não demoram a ser substituídas por outras, massivamente divulgadas pela mídia, rapidamente introjetadas pelas pessoas, em seu cotidiano e espaço privado.

O livro A produção subjetiva do cuidado: cartografias da estratégia saúde da família, organizado por Franco, Andrade e Ferreira, desafia a ordem, subverte o instituído, questiona a suposta verdade. Subdividido em oito capítulos, assinados por pesquisadores que compartilham dos mesmos substratos teóricos, vem somar-se a uma constelação de pesquisas sobre a micropolítica do trabalho em saúde, mas se destaca pela singularidade do espaço-tempofluxo no qual foi operada a vivência do estudo, bem como pela criatividade, ao tomar emprestado conceitos de variadas fontes e remodelá-los em uma metodologia inventiva, uma 'antropofagia metodológica', nas palavras dos autores, pois operam "ao mesmo tempo com uma razão instrumental, que auxilia na compreensão de alguns aspectos institucionais implicados com a questão em foco, e por outro lado uma 'não razão' que permite captar o que há de sensível, não visível, o que se forma como base nas intensidades circulantes entre sujeitos em relação, como parte importante na produção do cuidado" (p.17). 
Para lidar com territórios fluidos e existenciais, os autores recorreram aos aportes filosóficos de Espinosa, Deleuze e Guattari e optaram pela escolha e aplicação do método cartográfico, cuidadosamente apresentado nos capítulos 1 e 2, "A produção subjetiva da estratégia saúde da família" e "Sobre o uso de instrumentos cartográficos na pesquisa em saúde coletiva". Os textos, instigantes e desafiadores, provocam reações fortes no leitor. Não se fica incólume à proposta da pesquisa; há 'em ato' uma afecção que pode produzir identificação imediata, vontade de aprender, súbita indiferença, rechaço ou incompreensão. Os autores não se esquivam de revelar total implicação, afeto e entrelaçamento com o fenômeno pesquisado, e se intitulam pesquisadores cartógrafos.

Os cinco capítulos seguintes não abandonam a proposta metodológica e utilizam-na por meio de distintas técnicas de coleta de dados, conforme as especificidades dos fenômenos. Algumas dessas ferramentas são familiares às pesquisas qualitativas, como entrevistas, observações e grupos focais; outras são mais específicas, a exemplo da rede de petição e compromisso e do fluxograma descritor. O foco recai no processo de trabalho e nas tecnologias presentes no cotidiano das equipes de saúde da família, na cidade baiana de Itabuna. Munidos de 'lentes' muito especiais, pesquisadores da Universidade Estadual de Santa Cruz (Uesc) e seus parceiros revolvem o terreno institucional em que ocorrem as práticas, para revelar o 'trabalho vivo em ato', partindo das concepções de Merhy. Cartografam o trabalho em equipe (capítulo 3), as singularidades do trabalho do enfermeiro (capítulo 4), as práticas de cuidado dos agentes comunitários de saúde com os hipertensos (capítulo 5), a integralidade na atenção ao pré-natal (capítulo 6) e o acolhimento (capítulo 7). Os investigadores vão a campo e não poupam esforços para a compreensão dos saberes e das subjetividades inerentes aos seus objetos de pesquisa. Sempre presente está a imbricação entre pesquisadores e pesquisados, a compor o mesmo substrato: "A pesquisa produz um encontro do pesquisador consigo mesmo, em que os vários 'sujeitos em nós' se revelam na sua singularidade, operando ao mesmo tempo implicações diferentes com o objeto a ser estudado" (p.62).

Com criatividade, os autores ousam na construção teórico-metodológica e ancoram-se na análise institucional, esquizoanálise, caosmose e em conceitos como rizoma e desterritorizalização/reterritorialização, entre tantos. Abrem mão do 'conforto' das teorias hegemônicas para teorizar sobre a subjetividade inspirados, em Guattari e Deleuze: "A sensação que se tem é de perda de referenciais, o chão não há mais na medida em que novas possibilidades teóricas e metodológicas se tornam reais, contrariando métodos anteriores de investigação, mais estruturados" (p.65). Nesse aspecto, expõem a linha tênue em que se encontram. Sem abandonar a clareza de uma pesquisa científica, o 'rigor' no método, revelam total liberdade na condução dos estudos, o que constitui o ponto vulnerável de alguns capítulos. Os autores argumentam:

\footnotetext{
a pesquisa que propomos indica que a construção teórico-metodológica se dá pari passu às transformações ocorridas nas paisagens do campo de estudo ... Pesquisar assim é como surfar em uma onda, em que ao mesmo tempo o sujeito pesquisador conduz a pesquisa e é conduzido por ela, para caminhos às vezes desconhecidos a priori, fazendo desvios não programados, deparando-se com o inusitado, e muitas vezes operando como em uma dobra, no sentido deleuziano ... (p.47).
} 
O livro traz, de fato, uma contribuição metodológica significativa pelas teorias que propõe e utiliza. Desse modo, encoraja o leitor a experimentá-las, não só no campo da pesquisa, mas também na organização das práticas em saúde, ou seja, na gestão da micropolítica.

Ao esmiuçarem o processo de trabalho em saúde e a interação das tecnologias duras, leve-duras e leves na produção do cuidado, os capítulos evidenciam problemas frequentes em diversos estudos: dificuldade no acesso, baixa resolubilidade, fragmentação das ações, precariedade do trabalho, modelo de atenção centrado no procedimento e pouco atento ao usuário, filas de espera, baixo nível de integração na rede de serviços, o não cuidado etc. Contudo, para além das descrições dos problemas encontrados, propõem uma nova forma de resolvê-los e/ou apreendê-los, sem, no entanto, impor um protocolo ou uma diretriz geral. A inventividade, que tem inspiração em trabalhos anteriores de Donnangelo, MendesGonçalves, Campos, Cecílio, Merhy, entre outros importantes sujeitos da saúde coletiva, guarda estreita implicação com a res publica, daí não limitar qualquer possibilidade de agregar o novo e o inesperado em defesa da saúde universal, integral, equitativa, democrática, justa e solidária.

Os dados empíricos apresentados nos estudos de caso (capítulos 3 a 7) têm "capacidades virtuais ou atuais de produzir, inventar, transformar" (Baremblitt, 1992, p.185). Nesse aspecto, no processo de trabalho - em equipe, do enfermeiro ou do agente comunitário em saúde -, aponta para a força instituinte dos microprocessos, sendo essa a aposta dos autores para a mudança na produção do cuidado e, consequentemente, para a transformação do modelo de atenção à saúde. Para tanto, a pesquisa-ação apresentada no capítulo 7 mapeia uma realidade e uma intervenção, oferecendo aos leitores uma real dimensão prática do método, 'em ato'.

No derradeiro capítulo retomam-se o método, as questões teóricas e, partindo da categoria processo de trabalho, indaga-se a respeito das explicações que têm orientado as políticas de saúde: "ineficiência das políticas preventivas e... a falta de financiamento" (p.147). De maneira competente, arremata os capítulos antecessores, abrindo as cortinas e permitindo, com isso, novas luminosidades e diferentes perspectivas, antes ofuscadas. Em profícua interação com os trabalhos de Merhy, o autor engendra uma discussão acerca da 'reestruturação produtiva'. Argumenta que mesmo o processo de trabalho na saúde da família tem sido orientado pela lógica produtivista, em que se trata a saúde como um 'bem de troca', e defende que a reestruturação produtiva a priori não garante o cuidado. $\mathrm{O}$ argumento - que ademais perpassa todo o livro - é o de que o cuidado só pode ser garantido mediante o uso adequado das tecnologias, mas sem hierarquias entre elas e valorizando-se as subjetividades, as relações entre os sujeitos e o 'trabalho vivo em ato'. Para tanto, propõese uma transição tecnológica, possível apenas mediante fluxos em todas as direções, como um rizoma; gestões 'porosas' às necessidades dos trabalhadores e usuários - trabalhadores responsáveis pelo cuidado, usuários ativos na busca dos seus direitos e deveres em relação à saúde.

Assim, propor que a atenção primária à saúde/estratégia saúde da família seja a 'porta' do modelo de atenção ou proferir mudanças na organização da rede de serviços de saúde surtem efeitos paliativos ou limitados, ainda que constituam reestruturações importantes e impactantes. Caso não existam políticas que enfrentem a questão das tecnologias 
apropriadas ao cuidado, aos poucos todo e qualquer mecanismo de mudança é 'cooptado', e o processo de trabalho em saúde passa a atender a interesses coorporativos e a fazer brotarem 'demandas imaginárias'. No capítulo 2, os autores antecipam essa discussão:

Para uma 'transição tecnológica' seria necessário que a reestruturação produtiva avançasse para romper com as atuais estruturas do modelo biomédico, do processo produtivo centrado no ato prescritivo, organizando processos de trabalho mais relacionais. Se um processo de reestruturação não chega a esse patamar ele deixa de ser instituinte para se instituir como território já existente, faz assim uma reprodução do atual modo de produzir o cuidado (p.35).

Em linhas gerais, é disto que trata a obra: um convite à defesa da saúde como patrimônio das pessoas, perseguindo-se o cuidado como resultado de práticas responsáveis, como ética do humano (Boff, 2001) e como valor (Pinheiro, 2009).

\section{REFERÊNCIAS}

BAREMBLITT, Gregorio.

Compêndio de análise institucional e outras correntes: teoria e prática. Rio de Janeiro: Rosa dos Tempos. 1992.

BOFF, Leonardo.

Saber cuidar: ética do humano - compaixão pela terra. Petrópolis: Vozes. 2001.

\section{PINHEIRO, Roseni.}

Cuidado como valor: um ensaio sobre o (re)pensar a ação na construção de práticas eficazes de integralidade em saúde. In: Pinheiro, Roseni; Mattos, Ruben Araujo (Org.). Razões públicas para a integralidade em saúde: o cuidado como valor. Rio de Janeiro: Cepesc/ IMS/Uerj. 2009. p.15-28.

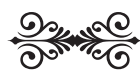

